\title{
Hematological profile of Khillar breed of cattle in Karnataka
}

\author{
K. Sripad ${ }^{1}$, Shrikant Kowalli ${ }^{1}$ and Raju Metri ${ }^{2}$ \\ 1. Animal Disease Diagnostic Laboratory and Information Centre, Belgaum, Karnataka, India; \\ 2. Veterinary Officer, Veterinary Dispensary, Department of Animal Husbandry and Veterinary Services, \\ Government of Karnataka, Kesti, Belgaum, Karnataka, India \\ Corresponding author: K. Sripad, email: drksripad@gmail.com, Cell: 91-9449293591. \\ SK: shrikantkowalli@rediffmail.com, RM: rajumetri@gmail.com. \\ Received: 19-03-2014, Revised: 05-04-2014, Accepted: 09-04-2014, Published online: 14-05-2014
}

doi: $10.14202 /$ vetworld.2014.311-314

How to cite this article: Sripad K, Kowalli S and Metri R (2014) Hematological profile of Khillar breed of cattle in Karnataka, Veterinary World 7(5): 311-314.

\begin{abstract}
Aim: The present study was undertaken with the objective of determining the reference values for hematological parameters for Khillar breed of cattle in general and in the subpopulations such as male, female and different age group of animals.

Materials and Methods: The present study was carried out at Khillar Cattle Breeding Farm, Bankapur, Karnataka. A total of sixty eight animals were used in the study. Animals were grouped based on sex into male and female and in the age groups 3-5 years, 6-10 years and above 10 years of age. Blood samples with anticoagulant were collected from these animals and hematological parameters were determined. Mean values were compared between males and females, and between different age groups.

Results: Mean and standard error values of all the hematological parameters for Khillar breed of cattle in general, male, female and different age groups of animals are tabulated. TEC, TLC, Hb, PCV and PLT values in males were significantly higher than female, whereas there were no significant differences in the mean hematological values between animals in the different age groups.

Conclusions: The present study reported the hematological values which could serve as baseline/reference values for Khillar breed in general, male, female and different age groups of Khillar breed of cattle. These reference values help in comparison of normal with various physiological, nutritional and deficiency conditions.
\end{abstract}

Keywords: hematological, Khillar breed, Karnataka, profile.

Abbreviations: TEC - Total erythrocyte count, TLC - Total leukoocyte count, Hb - Haemoglobin, PCV - Packed cell volume, PLT - Total platelet count, DLC-Differential leukocyte count

\section{Introduction}

In the recent past, preservation and conservation of the local germ plasm has gained priority and attempts are being made to improvise the indigenous cattle breeds due to their production potential. Among the local cattle breeds, Khillar breed is a good draught breed which is used regularly in farm practices. It is an unique cattle breed of Northern Karnataka and parts of Maharastra. The importance of hematobiochemical indices in animal husbandry is well acknowledged in cattle [1].

The study of blood constituents can provide valuable information about the general health of an animal and therefore, can be used for evaluating the health status of the animal. Observation of a deviation of certain blood parameters from their normal limits could be a guide for diagnosis or differential diagnosis of a disease condition [2]. Hematological profile being very important in evaluation of the health status of animals and clinical interpretation of laboratory data, is a prerequisite for diagnosis of several pathophysio-

Copyright: The authors. This article is an open access article licensed under the terms of the Creative Commons Attribution License (http://creativecommons.org/licenses/by/2.0) which permits unrestricted use, distribution and reproduction in any medium, provided the work is properly cited. logical and infectious disorders in cattle $[3,4,5]$. The complete blood count $(\mathrm{CBC})$ is an important and powerful diagnostic tool as a component of a minimum database. It can be used to monitor response to therapy, to gage the severity of an illness or as a starting point for formulating a list of differential diagnosis. Interpretation of the $\mathrm{CBC}$ can be divided into three sections: evaluation of the erythrocyte, leukocyte and platelets. Each of these parameters can be interpreted individually: however, integration of the data is important for the highest diagnostic yield [6]. Blood examination is also performed as a screening procedure to assess general health $[7,8]$. Hematological values are also indicators of stress and welfare of animals [9]. There is a need to establish breed-specific reference ranges for blood parameters for indigenous cattle breeds [10]. But there is paucity of information in the literature regarding the hematological values of Khillar breed of cattle.

Keeping these in points in view, the present study was undertaken at Khillar Cattle Breeding Farm, Bankapur, Karnataka during the year 2009-10 with the objective of determining the reference values for hematological parameters for Khillar breed of cattle in general, male, female and different age groups (above 3 -5 years, $6-10$ years and above 10 years of age). 
Table-1: Mean \pm SE of hematological parameters of all the 68 Khillar cattle breed.

\begin{tabular}{ll}
\hline Parameters & Mean \pm SE \\
\hline TEC $\times 10^{6}$ & $7.57 \pm 0.30$ \\
TLC $\times 10^{3}$ & $12.03 \pm 0.46$ \\
Hb (g/dl) & $10.11 \pm 0.34$ \\
PCV/Hct (\%) & $33.54 \pm 0.99$ \\
PLT x 10 & $374.35 \pm 15.42$ \\
MCV (fl) & $47.46 \pm 3.90$ \\
MCH (pg) & $13.59 \pm 0.32$ \\
MCHC (\%) & $31.72 \pm 1.82$ \\
Differential count & \\
N (\%) & $28.23 \pm 1.01$ \\
L (\%) & $62.32 \pm 1.09$ \\
E (\%) & $5.89 \pm 0.52$ \\
M (\%) & $1.50 \pm 0.21$ \\
B (\%) & $1.01 \pm 0.05$ \\
\hline
\end{tabular}

Table-2: Mean \pm SE of hematological parameters in male and female Khillar cattle breed

\begin{tabular}{lll}
\hline Parameters & Male $(\mathbf{n}=\mathbf{2 1})$ & Female $(\mathbf{n}=\mathbf{4 7})$ \\
\hline TEC $\times 10^{6}$ & $8.31 * \pm 0.45$ & $6.83 \pm 0.14$ \\
TLC $\times 10^{3}$ & $13.15^{*} \pm 0.63$ & $11.41 \pm 0.29$ \\
Hb $(\mathrm{g} / \mathrm{dl})$ & $11.00^{*} \pm 0.51$ & $9.21 \pm 0.16$ \\
PCV/Hct $(\%)$ & $35.75 * \pm 1.45$ & $31.33 \pm 0.52$ \\
PLT $\times 10^{3}$ & $312.60 * \pm 21.42$ & $236.10 \pm 9.39$ \\
MCV $(\mathrm{fl})$ & $43.54 \pm 1.34$ & $51.37 \pm 6.45$ \\
MCH $(\mathrm{pg})$ & $13.31 \pm 0.35$ & $13.87 \pm 0.29$ \\
MCHC $(\%)$ & $30.66 \pm 0.34$ & $32.78 \pm 3.29$ \\
Differential count & & \\
N (\%) & $27.85 \pm 1.49$ & $28.67 \pm 0.53$ \\
L (\%) & $63.21 \pm 1.57$ & $62.46 \pm 0.60$ \\
E (\%) & $5.91 \pm 0.77$ & $5.87 \pm 0.27$ \\
M (\%) & $1.10 \pm 0.23$ & $1.00 \pm 0.06$ \\
B (\%) & $1.32 \pm 0.50$ & $1.40 \pm 0.12$ \\
\hline
\end{tabular}

* - Significant difference at $P \leq 0.05$

Table-3: Mean \pm SE of hematological parameters in different age groups of Khillar cattle breed

\begin{tabular}{|c|c|c|c|}
\hline Parameters & above 3 years -5 years $(n=19)$ & $6-10$ years $(n=35)$ & above 10 years $(n=14)$ \\
\hline TEC $\times 10^{6}$ & $7.23 \pm 0.17$ & $6.51 \pm 0.26$ & $6.33 \pm 0.18$ \\
\hline TLC $\times 10^{3}$ & $12.29 \pm 0.29$ & $11.48 \pm 0.66$ & $10.74 \pm 0.12$ \\
\hline $\mathrm{Hb}(\mathrm{g} / \mathrm{dl})$ & $9.43 \pm 0.21$ & $8.88 \pm 0.33$ & $8.84 \pm 0.28$ \\
\hline $\mathrm{PCV} / \mathrm{Hct}(\%)$ & $31.85 \pm 0.69$ & $30.55 \pm 0.91$ & $30.13 \pm 0.73$ \\
\hline PLT $\times 10^{3}$ & $252.91 \pm 13.04$ & $212.3 \pm 13.59$ & $229.00 \pm 11.26$ \\
\hline $\operatorname{MCV}(\mathrm{fl})$ & $42.86 \pm 1.09$ & $59.68 \pm 11.28$ & $48.70 \pm 1.11$ \\
\hline $\mathrm{MCH}(\mathrm{pg})$ & $13.64 \pm 0.46$ & $14.34 \pm 1.22$ & $13.90 \pm 0.31$ \\
\hline $\mathrm{MCHC}(\%)$ & $35.28 \pm 5.35$ & $28.85 \pm 0.29$ & $28.60 \pm 0.12$ \\
\hline \multicolumn{4}{|c|}{ Differential count } \\
\hline $\mathrm{N}(\%)$ & $27.31 \pm 0.76$ & $28.02 \pm 0.45$ & $29.20 \pm 3.01$ \\
\hline $\mathrm{L}(\%)$ & $64.57 \pm 0.81$ & $62.90 \pm 0.81$ & $62.10 \pm 3.04$ \\
\hline$E(\%)$ & $5.49 \pm 0.36$ & $6.47 \pm 0.43$ & $6.10 \pm 0.87$ \\
\hline$M(\%)$ & $1.20 \pm 0.08$ & $0.80 \pm 0.15$ & $1.05 \pm 0.21$ \\
\hline $\mathrm{B}(\%)$ & $0.87 \pm 0.42$ & $1.10 \pm 0.30$ & $0.95 \pm 0.25$ \\
\hline
\end{tabular}

\section{Materials and Methods}

Ethical approval: While collecting blood samples, adequate precautionary measures were taken to minimize pain and / or discomfort to the animals and also collection of samples was carried out in accordance with the guidelines laid down by the International Animal Ethics Committee and prevailing local laws and regulations.

Study area: The Khillar Cattle Breeding Farm, Bankapur is located in Haveri district of Karnataka at a height of 594 meters above sea level, with Longitude $14.51^{\circ} \mathrm{N}$ and latitude $-75.26^{\circ} \mathrm{E}$ coordinates and belongs to Central dry agroclimatic zone. The area has a shallow to deep black soil pattern with an average temperature of $15.27^{\circ} \mathrm{C}$ to $37.19^{\circ} \mathrm{C}$, rainfall of zero to $1209 \mathrm{~mm}$ and humidity of 42.24 to $85.10 \%$ [11] .

Study group of animals: This study was undertaken at Khillar Cattle Breeding Farm, Bankapur, Karnataka. A total of 68 apparently healthy animals of different age groups and sex, formed the study group. The animals were in the age range of $3-13$ years of age, which were grouped based on the sex into male and female groups and based on the age into - above 3 - 5 years, 6-10 years and above 10 years age groups.

Collection of blood samples: About $10 \mathrm{ml}$ of blood sample was collected aseptically from jugular vein of each of these animals in sterile vacuntainer tube containing heparin [12] Samples were immediately transported to the laboratory on ice.

Analysis of samples: Blood samples were subjected to hematological analysis viz., TEC, TLC, Hb, PCV, PLT, and DLC using ERMA PCE -210(N) Hematology analyzer from Erma Inc, Tokyo [13]. The hematological indices, mean corpuscular volume (MCV), mean corpuscular hemoglobin $(\mathrm{MCH})$ and mean corpuscular hemoglobin concentration (MCHC) were calculated from the erythrocytic series values [14].

Statistical analysis: Results were tabulated and analyzed by using students ' $t$ ' test and analysis of variance [15].

\section{Results and Discussion}

Mean and standard error (SE) values of all the hematological parameters of 68 animals are tabulated in Table-1.

The mean and SE values of the hematological parameters of male and female groups are tabulated in Table-2. Means of some hematological parameters such as TEC, TLC, Hb, PCV and PLT were significantly higher in male $(\mathrm{P}>0.05)$ than in females. Mean values of all the hematological parameters of male and female Khillar cattle breed were compared with respective groups of Krishnavalley cattle breed. In male cattle, the mean PLT values of the Khillar group was significantly higher than that of Krishnavalley breed, whereas the 
mean value did not differ significantly in female group of Khillar and Krishnavalley breeds [16]. Mean values of all the hematological parameters (except platelet count) of male and female Khillar cattle breed were also compared with respective groups of Hallikar breed of cattle breed. It was observed that only mean TLC values of both male and female Khillar breed were significantly higher than respective groups of Hallikar breed, whereas in other parameters there was no significant difference [17].

The mean and SE values of all the hematological parameters in above 3 - 5 years, 6 - 10 years and above 10 years age groups are tabulated in Table-3. Comparative analysis of means of all the hematological parameters between - above 3 - 5 years, 6 - 10 years and above 10 years age groups, revealed no significant difference $(\mathrm{P}$ $>0.05$ ).

In the present study, we have adopted the approved and standard procedures for estimation of hematological values. Efficient tools were used for assessment or evaluation of normal health, various physiological status, diagnosis of infectious diseases, nutritional deficiencies or metabolic disorders, management problems of the farm which have a great relation to health status of the animal and also for interpretation of laboratory results [18]. Any deviation from the normal range is defined as pathological [5]. Whenever there are some abnormalities, then hematological values might aid in establishing a prognosis and / or developing a therapeutic plan, even if a specific diagnosis is lacking [19]. The changes in hematological constituents are important indicators of the physiological or pathological state of the animal [20]. The hematological values may vary depending on factors such as age, stage of growth, sex/gender, weather, season, stress, physical exercise of the animal and physiological well-being of the animal including reproduction and lactation status of the animal $[5,21]$. For this purpose gender wise and age group wise hematological reference values for a particular species or breed is a basic requirement [10]. These values may vary with the climatic, geographical and environmental conditions [22].

The hematological values reported in the present study can serve as the reference value / baseline data for male, female and different age groups of Khillar breed of animals. Blood samples were collected from apparently healthy Khillar breed animals of different sex and age, without any clinical or pathological manifestations. Perusal of literature did not indicate information on the hematological profile of the Khillar breed of cattle and these values can serve as reference value / baseline data for respective groups of Khillar breed of animals and the same can be used in future.

\section{Conclusion}

The hematological values reported in the present study for the entire study group, male, female and different age groups of Khillar breed of animals, may serve as reference values for respective groups of Khillar breed of cattle, which is an unique cattle breed adapted to existing climatic, nutritional, environmental and pathological environment of Northern Karnataka and parts of Maharastra. The data presented in this study can be used as a baseline to study the hematological alterations due to physiological status, pathological conditions, metabolic disorders and nutritional deficiencies and therefore has applications for diagnostic and / or therapeutic purpose.

\section{Authors' contributions}

KS supervised the overall research work. KS and SK participated in sampling and analysis of samples. KS and RM made available relevant literatures and carried out statistical analysis. All the authors participated in draft and revision of the manuscript. All authors read and approved the final manuscript.

\section{Acknowledgements}

The authors acknowledge the financial support from Institute of Animal Health and Veterinary Biologicals, Hebbal, Bangalore. The authors sincerely acknowledge the technical support of the laboratory technician of Animal Disease Diagnostic Laboratory and Information Centre, Belgaum, Karnataka, in laboratory analysis of samples.

\section{Competing interests}

The authors declare that they have no competing interests.

\section{References}

1. Radostits, O.M., Gay, C.C., Blood, D.C. Hinchcliff, K.W. (2003) Veterinary Medicine. Elsiever Science Ltd., USA. $9^{\text {th }}$ Edn. p148.

2. Omer, S.A., Salawa, M.E., Khougali, H., Agab. and Gussey, Samad, H.A. (2010) Studies on some biochemical and haematological indices of Sudanese camels (Camelus dromedarius) Published in Sudan University of Science and Technology Bulletin. p1-7.

3. Mc. Dowell, L.R. (1992) Minerals in animal and human nutrition. Academic press.Inc., San Diego, California. p112.

4. Opera, M.N., Ike, K.A. and Okoli, I.C. (2006) Hematology and plasma biochemistry of the wild adult African Grasscutter. J. Am. Sci., 2:17-22.

5. Kaneko,J.J., Harvey, J.W. and Bruss, M.L. (1997) Clinical biochemistry of domestic animals. $5^{\text {th }}$ Edn. Academic press. New York, p932.

6. Barger, A.M. (2003) The complete blood cell count : a powerful diagnostic tool. Vet Clin North Am Small Anim Pract, 33:1207-1212.

7. Gutienez De Lar, J.H., Warnick, A.C., Cowley, J.J. and Hentages, J.F. (1971) Environmental physiology in the subtropics. I. Effect of continuous environmental stress on some hematological values of beef cattle. J. Anim. Sci. 32: 968-973.

8. Jain, N.C.( 1993). Essentials of veterinary hematology. Lea and Febiger, Philadelphia, p1-18.

9. Anderson, B.H., Watson, D. L., Colditz, I.G. (1999). The effect of Dexamethasone on some immunological parameters in cattle. Vet. Res. Commun., 23: 399-413.

10. Conradie van Wyk, I \& Goddard, A., De, B.M., Bronsvoort, C., Coetzer, J.A.W., Booth,C., Hanotte, O., Jennings, A., Kiara, H., Mashego, P., Muller, C., Pretorius, G., Poole, E.J., Thumbi, S.M., Toye, P.G., Woolhouse, M.E.J. and 
Penzhorn, B.L. (2013) Hematological profile of East African short-horn zebu calves from birth to 51 weeks of age. Comp Clin Pathol. 22: 1029-1036.

11. http://www.kvkhaveri.org. Accessed on 15-02-2014.

12. Sharma,M.C., Pankaj Kumar., Joshi, C. and Harjeet Kaur. (2006) Status of Serum Minerals and Biochemical Parameters in Cattle of Organized Farms and Unorganised Farms of Western Uttar Pradesh. Asian J. Anim. Vet. Adv. 1(1): 33-41.

13. Benjamin, M.M. (2001) Outline of Clinical Veterinary Pathology, $2^{\text {nd }}$ edn. Kalyani Publishers, New Delhi. p31, 35-36, 51, 62, 71, 187-189, 203.

14. Dacie, J.V. and Lewis, S.M. (1991) Practical Hematology. Churchil Livingstone. Edinburgh, UK. $7^{\text {th }}$ Edn. p30.

15. Snedecor,G.W. and Cochran,W.G. (1968) Statistsical Methods, $5^{\text {th }}$ edn, Oxford and IBH publishing Co., Mumbai, India Page no. 361-362.

16. Sripad, K., Shrikant Kowalli and Raju Metri. (2014) Serum biochemical and hematological profile of male, female and different age groups of krishnavalley breed of cattle in Karnataka. Int. J. Phar. Bio. Sci. 5(2). 176-180.

17. Lankesh, P. (2013) Hematological and biochemical profile in
Hallikar cattle. MVSc Thesis submitted to KVAFSU, Bidar.

18. Shil, S.K. and Shaikat, A.H. (2010) MS Thesis submitted to Chittagong Veterinary and Animal Sciences University, Khulshi, Chittagong, Bangladesh.

19. http://veterinarynews.dvm360.com/dvm/ Veterinary+ Food+Animal/Blood-work-revelations-limitations-forcattle/ArticleStandard/Article/detail/416155. Accessed on 19-02-2014.

20. Ammed Ijaz, Gohar, A., Ahmed, N. and Ahmed, M. (2003) Hematological profile in cyclic and noncyclic and endometritic cross breed cattle. Int. J. Agr. Bio. 5(3): 332334.

21. Doornenbal, H., Tong, A.K.W., Martin, A.H. and Sather, A.P. (1983) Studies on the performance, development and carcass composition of growing pig: effect of sex, feeding regime and age on blood serum parameters. Can. J. Anim. Sci. 83: 977-984.

22. Mahima, Krishna, V.S., Amit, K.V., Vinod, K., Shankar, K.S. and Debashis, R. (2013) Hematological and serum biochemical profile of apparently healthy Hariana cattle heirfers in Northern India. Pak. J.Biol. Sci. 16(21): 14231425.

\section{$* * * * * * * *$}

